Revista de Derecho YACHAQ

ISSN: 1817-597x (impresa) / ISNN: 2707-1197 (en linea)

Centro de Investigación de los Estudiantes de Derecho (CIED)

Universidad Nacional de San Antonio Abad del Cusco

N. ${ }^{\circ} 10-2019$

[pp. 39-45]

Fecha de recepción: 09/08/19

Fecha de aceptación:15/09/19

\title{
Legitimidad política y consumo. Reflexiones e interrogantes
}

\section{Political Legitimity and Consumption Reflections and Interrogants}

\author{
Juan Antonio Gómez García ${ }^{[\star]}$
}

\begin{abstract}
RESUMEN: el presente trabajo aborda críticamente la cuestión de la legitimidad política en el actual contexto postmoderno, desde la óptica del consumo y del ciudadano-consumidor, en tanto que elemento que ha adquirido especial protagonismo en la definición de lo político.
\end{abstract}

ABSTRACT: this work critically addresses the issue of political legitimacy in the current post-modern context, from the perspective of consumption and citizen-consumer, as an element that has acquired special prominence in the definition of the political.

PALABRAS CLAVE: legitimidad, postmodernidad, consumo, ciudadanía, política.

KEYWORDS: legitimacy, post-modernity, consumption, citizenship, politics.

\section{LA POLÍTICA HOY: CRISIS Y ECLIPSES}

El filósofo italiano Giorgio Agamben afirma, en su espléndido libro Medios sin fin, que la política parece encontrarse actualmente en un eclipse prolongado (Agamben, 2001, p. 9). Hoy se habla usualmente de crisis para hacer referencia al estado de la política en nuestras sociedades, pero el empleo aquí del término eclipse me parece mucho más preciso.

En efecto, eclipse significa 'desaparición, ausencia, evasión', en el mejor de los casos 'os- curecimiento'; a diferencia del término crisis, que implica, a mi juicio, una toma de postura de distanciamiento con respecto a algo, pero sin perderlo de vista todavía como referente principal de juicio. Eclipsar, sin embargo, implica ya relegar lo eclipsado a una posición secundaria con respecto a aquello que se eclipsa, llegándose así a perderlo de vista. Según Agamben, el eclipse de la política ha supuesto precisamente relegar a una posición subalterna a la política con respecto a la economía, al derecho, etc., de tal modo que ha desaparecido, ha sido oscurecida por estos.

[*] Profesor de Filosofía del Derecho en la UNED, Departamento de Filosofía Jurídica, Facultad de Derecho. Contacto: jagomez@der.uned.es 
Ofrecer una explicación de las razones constituye, obviamente, una cuestión muy compleja que sobrepasa con mucho el limitado alcance de la presente reflexión; no obstante, en términos generales, creo que una de sus causas fundamentales estriba en, podríamos decir, la actual pérdida de conciencia generalizada del rango ontológico de la política, lo cual ha supuesto, asimismo, la pérdida de su papel central en la vida de las personas. La clásica concepción griega de la política, ejemplarmente significada por la noción aristotélica ${ }^{[1]}$, ha quedado definitivamente eclipsada en el mundo postmoderno bajo un patrón estrictamente esteticista de lo social, la cual la ha reducido, en el mejor de los casos, a lo simplemente formal, a lo puramente nominal y, por lo tanto, a la mera apariencia.

Esto ha derivado en un vaciamiento progresivo, desde su misma raíz, de sus categorías y conceptos fundamentales, cuyo lugar propio ha sido ocupado por otro tipo de categorías y conceptos de naturaleza, fundamentalmente, económica y jurídica, que han venido a erigirse en los referentes únicos de la legitimidad política, eclipsando así, como decía, a la auténtica política. Se entiende así que se esté buscando lo político en experiencias y en fenómenos no considerados prima facie -incluso, bajo criterios modernos, esto es, democráticoliberales-como políticos. Por ejemplo, siguiendo con Agamben, que se indague en la vida natural de los hombres, en la zoé (ámbito excluido tradicionalmente del ámbito propiamente político), la cual está pasando a ocupar el centro de la polis, como decía Foucault: “"lo que hoy está en juego es la vida", y la política se ha convertido, por ello mismo, en biopolítica» (Foucault, 2001, pp. 209-216).

Desde el momento en que lo político queda eclipsado por otros ámbitos -y consiguientemente, evacuado-, su espacio se ve invadido por conceptos y categorías ajenas. Como síntoma de este vaciamiento, me parece especialmente interesante lo que Agamben (2001) refiere a propósito de lo que denomina como estado de excepción, esto es, «la suspensión temporal del orden jurídico» (pp. 9-10), en tanto que característica regular de lo político en nuestras democracias actuales, y que viene a significar la ocupación aplastante del orden político por parte del orden jurídico, hasta el punto de haberse convertido en su estructura fundamental. Ciertamente, la declaración de este estado de excepción es algo cada vez más recurrente en nuestras democracias, de tal modo que en el establecimiento de la excepcionalidad jurídica legitimada por la vía de la apelación a una permanente situación de peligro grave que, además, viene a ser reproducida de modo subliminal o subrepticio para perpetuarla —uno de los más inquietantes ejemplos es lo que se ha venido a llamar como derecho penal del enemigo - es donde se juega, de algún modo, lo político. Es muy pertinente aquí la siguiente cita que Agamben realiza de Walter Benjamín, quien ya lo predijo, en buena medida, en el contexto de los totalitarismos del siglo pasado: «La tradición de los oprimidos nos enseña que el estado de excepción en que vivimos es la regla» (p. 15). $Y$ es que bajo el actual modelo postmoderno, el cual -lo anticipo ahora - tiene uno de sus pilares cardinales en la idea de consumo como criterio de legitimación política, ¿hay algo que sea más propio del consumo que la producción y el mantenimiento de esta sensación de «peligro grave permanente»? He aquí, a mi juicio, un punto de reflexión fundamental para comprender el lugar de lo político hoy ${ }^{[2]}$.

Por otra parte, el eclipse de lo político se explica también por la actual indiferencia entre lo público

[1] Recuérdese la célebre afirmación contenida en la Política que venía a definir al hombre como animal político: «el que no puede vivir en sociedad, o no necesita nada por su propia suficiencia, no es miembro de la ciudad, sino una bestia o un Dios» (Política, I, 1253 a 2-3, 29). Según esto, la cuestión hoy, a la luz de un debate eminentemente político, estribaría en determinar hasta qué punto se ha producido tal endiosamiento y/o bestialización del sujeto político en el contexto político presente.

[2] No hay más que ver el abusivo empleo que se viene haciendo por parte de los actuales ejecutivos españoles, en su acción política cotidiana, de la figura del Decreto-ley, el instrumento legislativo constitucionalmente previsto para las situaciones de extraordinaria y urgente necesidad (art. 86 de la Constitución española). 
y lo privado -lo cual constituye un hecho completamente nuevo en el contexto cultural democrático contemporáneo, desde la neta diferenciación entre ambos espacios que forjó y culminó la Modernidad liberal - y que, como dice Agamben, se ha erigido en la auténtica matriz oculta del espacio que se presenta como político en la actualidad, en este caso, referido bajo la siniestra metáfora del campo de concentración. Con ello se alude al fenómeno del confinamiento de las personas, sin ninguna clase de presupuesto ni de garantía judicial, en espacios concretos y cerrados, por su adscripción a un colectivo genérico determinado por encima de su individualidad propia. Este tópos aniquila la diferencia entre lo público y lo privado dejando a la persona al albur de las condiciones y del funcionamiento sistémico de este espacio, sin que le quepa la posibilidad de oponerse y, mucho menos, de resistirse. Es importante aquí plantearse la siguiente cuestión: ¿dónde puede encontrarse aquí lo político -incluso, en su noción liberal-, como expresión de la autonomía y de la libertad de la persona?

Mucho tiene que ver con ello la también actual, podríamos decir, desnaturalización del lenguaje, el cual ha sido objeto de una flagrante expropiación por la vía de su hipertrofia; en última instancia, de su vaciamiento. De nuevo nos viene aquí a la cabeza el Foucault de Las palabras y las cosas, en su diagnóstico del extremo nominalismo que constituye todo discurso - especialmente, el político- en las sociedades democráticas en las que vivimos. Ciertamente, esto supone el relegamiento de lo político a la mera esfera del gesto; como dice Agamben «a la esfera de los medios puros totalmente a parte de cualquier relación con sus fines, y que ha devenido hoy la esfera propia de lo político» (p. 10).

Bajo estas ideas generales, pretendo reflexionar aquí sobre las consecuencias que está teniendo todo esto en el plano de la legitimidad política -a mi juicio, la auténtica «piedra de toque» de lo político, al menos desde la modernidad, que como es sabido, es el momento en que se consuma la separación entre los distintos órdenes del conocimiento y de la acción humana- en nuestras democracias actuales. La noción de «legitimidad política» es aquí fundamental, ya que nos permite designar y establecer el auténtico y profundo tópos de lo político.

\section{LA CUESTIÓN DE LA LEGITIMIDAD POLÍ- TICA HOY}

Cada vez se habla menos de la legitimidad en el ámbito de la filosofía política y jurídica actual. La problemática que entraña esta noción se viene solventando hoy mediante la apelación genérica al procedimentalismo deliberativo democrático, el cual, en términos generales, viene a reducir la legitimidad política a la mera legalidad procedimental. He aquí la razón definitiva para cerrar cualquier debate sobre lo político, so pena de ser tildado como extrademocrático o antidemocrático si uno se ubica fuera de estos límites. De este modo, se cancela unívocamente cualquier tentativa de buscar otras razones (Gómez, 2014).

Partiendo de aquí, la reducción de la legitimidad a la legalidad consensuada hic et nunc supone limitarla a una idea - podríamos decir-minimalista; esto es, a su consideración meramente cuantitativa desde indicadores empíricos basados en criterios de medición. Son, pues, las encuestas, los estados de opinión, las tendencias demoscópicas, los cálculos y análisis de los datos electorales, etc., las que marcan, fundamentalmente, las pautas de la legitimidad política postmoderna actual, de modo que las políticas, las normas jurídicas y las instituciones son legítimas cuando están respaldadas por una actitud positiva de los ciudadanos en el marco de las reglas del juego democrático. Lo legítimo se ve, así, como algo en buena medida, coyuntural, relativo, incluso, fungible.

Sin embargo, de este modo creo que se está traicionando de raíz la misma noción de legitimidad, la cual supone, por el contrario, la permanente necesidad de razones, de fundamentos lo suficientemente sólidos y dinámicos para justificar la creencia en el poder político y, consecuentemente, la obediencia a sus normas. Por definición, la legitimidad política implica apertura en la consideración y en el ejercicio de lo político. Por lo tanto, es inevitable plantearse de inmediato las siguientes cuestiones: ¿acaso no es esta la lógica del funcionamiento del mercado y de su motor principal, el consumo?, ¿valen solamente el consumo, y los modos en que se induce y se opera el consumo, como patrones de relación y de vínculo entre las personas, para sostener una determinada legitimidad política?, ¿cabe 
sostener en puridad la legitimidad política en una democracia bajo estos presupuestos y pautas?; en último término, ¿cabe propiamente legitimarse un discurso político democrático por el simple hecho de presentarse como un buen producto de consumo?

\section{DEMOCRACIA, COMUNICACIÓN Y MASS- MEDIA: LAS DEMOCRACIAS - ESPECTÁ- CULO DE NUESTROS DÍAS}

He aquí una de las claves hermenéuticas fundamentales para comprender el antes indicado eclipse de la política en la actualidad. El modelo vigente, sostenido sobre perspectivas mercadotécnicas, ha impuesto una forma de relación entre las personas focalizada desde los patrones del show-bussines, del espectáculo, hasta el punto de que podemos afirmar abiertamente que nuestra politicidad se ejerce hoy —-más bien se intuye - tras el rutilante formato de democraciasespectáculo, orquestadas y dirigidas, en gran medida, por los medios de comunicación de masas y sus tendencias de opinión.

El lenguaje se está viendo forzado, hipertrofiado y expropiado como nunca en la historia. Ni el más radical de los nominalistas tardomedievales hubiera podido imaginar que se podría llegar al actual estado de cosas con el lenguaje. La presente postmodernidad ha reducido todo pensamiento y toda acción humana a mero discurso en el mejor de los casos; cuando no a simple apariencia de discurso. La correspondencia entre las palabras y las cosas es hoy una vana ilusión de utópicos soñadores y de retrógrados nostálgicos. Los procesos de descontextualización y de ulterior recontextualización de los hechos brutos, efectuados permanentemente por parte de los mass-media en discursos parcialistas e interesados, se han erigido en los referentes discursivos dominantes de las tendencias sociales, hasta el punto de que, tanto los ciudadanos como los actores políticos institucionales, han quedado constreñidos a lo recontextualizado por los medios de comunicación de masas. De este modo, la apariencia de discurso resultante viene a constituirse como el único espacio posible de discusión política, quedando prácticamente desterrado lo real —si acaso, se llegan a adivinar destellos lejanos, tras los bastidores de la fachada espectacular con la que se muestra-, tanto para el poder político como para los ciudadanos (Serres M., 1996, pp. 220-221).

Así, pues, la esfera de lo político se ha visto reducida, como sabiamente indica Agamben, a la pura esfera del gesto. Se ha impuesto, pues, una suerte de estética del consumo como único modo posible de aparecer - si es que aspira a tener éxito- de todo lo que se nos presenta como político. Los mass-media constituyen lo político, con independencia de los fines de este, efectuando así, radicalmente, su separación y su emancipación con respecto a aquellos. En términos aristotélicos, la causalidad final se ha visto cercenada violentamente por la causalidad eficiente y por la formal, de tal modo que tenemos actores y discursos políticos carentes de fines. Los actores políticos actúan en estas sociedades democrático-espectaculares a diario bajo la agenda política marcada por los massmedia, los cuales desempeñan la función de establecer los temas de atención pública por su enorme capacidad de influencia para inducir y atraer la atención de los ciudadanos. Se relega - cuando no se elimina - así la argumentación política y se determina el diálogo político en este escenario cuyo guión o libreto se encuentra fijado de antemano por los mass-media, quedándole a los actores políticos el mero papel de gestualizarlo públicamente.

Surge ahora la siguiente cuestión: ¿cabe comprender la legitimidad política en un plano puramente estético?, ¿cabe hablar de legitimidad política por la sola vía de una estética del consumo? En caso afirmativo, ¿qué consecuencias tiene todo esto para lo político?

\section{EL CIUDADANO POSTMODERNO: UN SU- JETO-OBJETO POLÍTICO}

Pensar la legitimidad política desde el consumo, en tanto que modo estructural de comprensión de la misma, implica considerar al auténtico protagonista de la política, el ciudadano, también, desde esta perspectiva. Desde el momento en que la lógica del consumo se nos presenta como modo estructural de lo político, el ciudadano se nos aparece también como un consumidor, como un sujeto que se identifica y se determina políticamente como consumidor de un determinado producto que se le vende en el mercado como político. 
Zygmunt Bauman ha descrito con gran lucidez cómo funciona la lógica del consumo desde presupuestos sociológicos en el contexto de las actuales sociedades postmodernas (sociedades líquidas las llama Bauman), y que se puede reducir al siguiente esquema - tal vez, demasiado simplificador de la explicación del autor, pero creo que muy interesante aquí para comprender esta cuestión-:

El destino final de todos los productos en venta es el de ser consumidos por compradores; los compradores desearán comprar bienes de consumo si, y solo si, ese consumo promete la gratificación de sus deseos, de tal modo que el precio que el cliente potencial en busca de gratificación está dispuesto a pagar por los productos en oferta dependerá de la credibilidad de esa promesa y de la intensidad de sus deseos. (Bauman, 2007, pp. 23, 24)

Así, pues, las elecciones y las decisiones de consumo determinan y conforman al consumidor, de tal modo que las sociedades resultantes (las sociedades de consumidores) son resultado de la cantidad y la calidad de los encuentros de los potenciales consumidores con sus potenciales objetos de consumo, los cuales van constituyendo una trama de relaciones.

Lo político queda identificado y explicado bajo este modelo como un producto más de mercado y, como tal, con la vocación y la función de ser consumido, al igual que el resto de mercancías. La ciudadanía se ejerce, pues, consumiendo tal producto y la politicidad de estas sociedades de consumidores se determina por la naturaleza, las condiciones y los modos en que tales actos de consumo de realizan. En estas sociedades de consumidores-ciudadanos todo es susceptible de ser consumido, de ser objeto de consumo. $Y$ cuando decimos todo, queremos decir eso: todo, ya que también el ciudadano en sí mismo se constituye como un objeto más, como cualquier otro, sometido a la dinámica del mercado y del consumo, los reinos de la incertidumbre y de la fluctuación por antonomasia. Y es que de ahí resulta una trama de relaciones interhumanas -no sé si pueden llamarse propiamente sociales; en ningún caso, comunitarias - que vienen a conformar una, podríamos decir, sociedad de la incertidumbre, en la cual rige por doquier la indeterminación; una so- ciedad en la cual los individuos proyectan y deben proyectar, en una suerte de performance permanente, sus propias vidas bajo los vaivenes constantes, y las evanescentes manifestaciones de tal incertidumbre latente. La persona, en tanto reducida totalmente a su condición de consumidor, vive hoy en estados transitorios y volátiles que dan como resultado también vínculos humanos de estas características —en el mejor de los casos_, imperando más bien el desarraigo y la desvinculación, en suma, la progresiva decrepitud de los vínculos sociales.

Surge aquí ese curioso concepto del marketing político - tan de moda hoy-, que no es otra cosa que el continuo diseño de la gestualización política que, en cada momento, debe efectuar el actor político de turno en el escenario candente de la política-espectáculo - repárese aquí en la chocante expresión política de gestos, auténtico gurú de los actores y de los analistas políticos hoy-. La aplicación de los principios y de las técnicas del management a la política está comportando que se trate al votante como consumidor, en razón del supremo acto de consumo político de nuestras democracias que es el ejercicio periódico del voto, sometido, en tanto que tal acto de consumo, a la volatilidad y volubilidad del consumidor de turno. En esto parece consistir lo que se viene a denominar, un tanto eufemísticamente, gestión política para caracterizar la flexibilidad y el pragmatismo que ha de atesorar cualquier opción política que se precie.

De esta manera, tiene lugar la apropiación, por parte del mercado, de la totalidad del espacio en que se desenvuelve la vida de las personas, incluso, del espacio que media entre ellos, de su espacio común (el espacio político por naturaleza). A partir de aquí se entiende por qué la lógica y el fenómeno del consumo adquieren el rango político tan fundamental que ostentan en el contexto de las actuales sociedades postmodernas. La prudencia y la sensatez, virtudes políticas por excelencia, quedan también eclipsadas por esta lógica del consumo, y los proyectos políticos se caracterizan así por su coyunturalidad y por responder al egocentrismo que son propios de ella. El consumo no atiende al largo plazo, sino a la satisfacción rápida e inmediata del deseo del sujeto, y los objetivos comunes y permanentes se sacrifican a estas exigencias de instantaneidad; los proyectos políticos a largo plazo no cuadran aquí 
y, por supuesto, la idea de sacrificio individual queda desterrada en aras de cualquier proyecto futuro que pueda ser justo y beneficioso para todos.

Por lo tanto, se ha producido el abandono de las ideas políticas fuertes, esto es, de aquellas ideas que tienen, y pretenden tener, capacidad real de fundamentación y de transformación social. De ahí que, como dice Ignatieff (2014), «la política se haya convertido primordialmente en el arte del aquí y ahora», en un particular espacio de gestión donde el líder político se caracteriza por su habilidad para sacar el máximo provecho de las coyunturas, propiciadas en gran medida, a su vez, por los flujos y corrientes de opinión diseminados por doquier, por parte de los mass-media.

Tiene mucha razón Jean Baudrillard (1989) cuando afirma que «el discurso político en las sociedades postmodernas se articula estructuralmente como un discurso de los objetos» (pp. 5-16). La pregunta ahora es iqué nos queda aquí de la clásica concepción moderna de ciudadanía? Parafraseando la última locución del protagonista de la famosa novela de Umberto Eco, El nombre de la rosa, me temo que tan solo el nombre.

\section{A MODO DE CIERRE}

No es fácil ofrecer respuestas a las interrogantes que nos han ido surgiendo anteriormente. He intentado esbozar una fenomenología de lo político en nuestras democracias actuales que permita, de alguna manera, incitar al pensamiento y abrir debates, más que ofrecer conclusiones cerradas. $\mathrm{He}$ aquí una recapitulación:

1) Desde la constatación inicial del actual eclipse de la política bajo el modo universal del consumo, la politicidad se cifra hoy en la mera elección, por parte del ciudadano-consumidor, entre diferentes opciones, cada vez más similares e indiferentes entre sí, y que, como tales opciones, se constituyen en marcas, personalidades o lemas más o menos atractivos, exhibidos en cada convocatoria electoral con un marketing que en nada se diferencia ya de cualquier campaña publicitaria para vender cualquier producto. Parece que esto ha erosionado profundamente lo común y, consiguientemente, los vínculos políticos entre las personas.
2) El mercado se ha apropiado, pues, del espacio político radicalizando la concepción liberal moderna de lo político que establece nítidamente límites entre lo público y lo privado y, por lo tanto, disolviendo su clásica concepción de la ciudadanía como algo que atañe a la racionalidad y a la responsabilidad del sujeto político pensante con respecto a su objeto. Se ha revelado como una mixtificación de lo real el viejo presupuesto moderno, en virtud del cual el sujeto y el producto (objeto) se encuentran inicialmente en una esfera de contemplación que pasa después a la esfera de la acción, en razón de un proceso analítico, calculístico, racional. Bauman nos enseña, por el contrario, lo siguiente:

Bajo el actual modelo de sociedad de consumidores, esta posición ha cambiado sustancialmente, puesto que el sujeto-consumidor está llamado constantemente a la acción, a la disposición, al manejo, a la apropiación, al uso y al descarte de los productos de consumo, más que a la acción predeterminada por un plan previo. (Bauman, 2007, p. 24)

La soberanía del consumidor se está mostrando como una ilusión y lo que se nos viene presentando como la revolución consumista está consistiendo, en el fondo, en un progresivo emborronamiento de los límites entre sujeto y objeto, entre el elector y lo potencialmente elegible en el escenario del mercado. Por eso, hablamos con Agamben de eclipse, más que de crisis de la política, al haberse suprimido la distancia crítica que media entre sujeto y objeto de consumo, sobre el que se sustenta la clásica concepción moderna de la política: el liberalismo democrático moderno.

3) La subjetividad política postmoderna parece haberse reducido a la condición de mero objeto que, como tal objeto, es susceptible de ser vendido para ser consumido. De este modo, el acto de consumo está pasando a convertirse en el auténtico acto de afirmación política, en virtud del cual el sujeto-objeto político de consumo se hace visible y se reafirma ante los otros, llamando su atención y adquiriendo así entidad propia. Se trata, en definitiva, de 
convertirse en un producto deseable y deseado más allá de la grisura y de lo amorfo de la masa, de ahí la necesidad — se dice hoy — de reinventarse, de reconvertirse permanentemente por parte del sujeto consumidor-objeto de consumo para no perder su presencia en el mercado de lo político, en una suerte de relato (ficción, ilusión) sobre sí mismo que salvaguarde tal presencia, de modo que la virtud política que se proclama hoy como más útil es la flexibilidad, la disposición y la presteza para abandonar compromisos y lealtades que, de algún modo, puedan dotarle de excesiva rigidez.

4) La lógica del consumo es la lógica de lo excepcional; el objeto de consumo debe resultar excepcional, debe interpelar la atención y el deseo del consumidor por su carácter exclusivo, único. Desde una transposición de esta lógica a lo político creo que se entiende mejor la lógica del estado de excepción que rige hoy la política, solamente de esta manera perceptible - en muchos casos solo intuible- desde su ya dilatado eclipse.

\section{REFERENCIAS BIBLIOGRÁFICAS}

Agamben, G. (2001). Medios sin fin, notas sobre la política. (A. Gimeno Cuspinera, trad.) Valencia: Pre-textos.

Baudrillard, J. (1989). Publicidad absoluta, publicidad cero. Revista de Occidente (92), pp. 5-16.

Bauman, Z. (2007). Vida de consumo. (M. Rosenberg, \& J. Arrambide, trads.) Madrid: Fondo de Cultura Económica.

Foucault, M. (2001). Nacimiento de la biopolítica. (Á. Gabilondo, ed.) Barcelona: Paidos.

Gómez García, J. A. (2014). Legalidad y legitimidad en el Estado contemporáneo. Madrid: Dykinson.

Ignatieff, M. (2014). Fuego y cenizas. Éxito y fracaso en la política. (F. Beltrán, trad.) Madrid: Taurus.

Serres, M. (1996). La Comunicación. Barcelona: Hermes I.

Serres, M. (1996). La comunicación. Hermes I. (R. Paez, trad.) Barcelona: Anthropos. 